\title{
Prevalence and clinical impact of Streptococcus pneumoniae nasopharyngeal carriage in solid organ transplant recipients
}

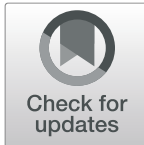

\author{
Cristina Roca-Oporto ${ }^{1,2 \dagger}$, Tania Cebrero-Cangueiro ${ }^{1,2,5 \dagger}$, María Luisa Gil-Marqués ${ }^{1,2}$, Gema Labrador-Herrera ${ }^{1,2}$, \\ Younes Smani ${ }^{1,2}$, Francisco Manuel González-Roncero ${ }^{3}$, Luis Miguel Marín ${ }^{4}$, Jerónimo Pachón ${ }^{2,5}$, \\ María Eugenia Pachón-Ibáñez ${ }^{1,25^{*}}$ (D) and Elisa Cordero ${ }^{1,2}$
}

\begin{abstract}
Background: S. pneumoniae is the leading cause of community-acquired pneumonia in the solid organ transplant recipient (SOTR); nevertheless, the prevalence of colonization and of the colonizing/infecting serotypes has not been studied in this population. In this context, the aim of the present study was to describe the rate, characteristics, and clinical impact of S. pneumoniae nasopharyngeal carriage.
\end{abstract}

Methods: A prospective observational cohort of Solid Organ Transplant recipients (SOTR) was held at the University Hospital Virgen del Rocío, Seville, Spain with the aim to evaluate the S. pneumoniae colonization and the serotype prevalence in SOTR. Two different pharyngeal swabs samples from 500 patients were included in two different seasonal periods winter and spring/summer. Optochin and bile solubility tests were performed for the isolation of thew strains. Antimicrobial susceptibility studies (MICs, mg/l) of levofloxacin, trimethoprim-sulfamethoxazole, penicillin, amoxicillin, cefotaxime, ceftriaxone, erythromycin, azithromycin and vancomycin for each isolate were determined by E-test strips. Capsular typing was done by sequential multiplex PCR reactions. A multivariate logistic regression analysis of factors potentially associated with pneumococcal nasopharyngeal carriage and disease was performed.

Results: Twenty-six (5.6\%) and fifteen (3.2\%) patients were colonized in winter and spring/summer periods, respectively. Colonized SOT recipients compared to non-colonized patients were more frequently men (79.5\% vs. $63.1 \%, P<0.05)$ and cohabitated regularly with children (59\% vs. $32.2 \%, P<0.001)$. The most prevalent serotype in both studied periods was 35B. Forty-five percent of total isolates were included in the pneumococcal vaccine PPV23. Trimethoprim-sulfamethoxazole and macrolides were the less active antibiotics. Three patients had nonbacteremic pneumococcal pneumonia, and two of them died.

Conclusions: Pneumococcal colonization in SOTR is low with the most colonizing serotypes not included in the pneumococcal vaccines.

Keywords: Streptococcus pneumoniae, Solid organ transplant recipients and nasopharyngeal carriage

\footnotetext{
* Correspondence: mpachon-ibis@us.es

${ }^{\dagger}$ Cristina Roca-Oporto and Tania Cebrero-Cangueiro contributed equally to this work joint first authors.

${ }^{1}$ Clinical Unit of Infectious Diseases, Microbiology, and Preventive Medicine Infectious Diseases Research Group Institute of Biomedicine of Seville (IBiS), University of Seville/CSIC/University Hospital Virgen del Rocío, Seville, Spain ${ }^{2}$ Institute of Biomedicine of Seville (IBiS), University of Seville/CSIC/University Hospital Virgen del Rocio Seville, Seville, Spain

Full list of author information is available at the end of the article
}

(c) The Author(s). 2019 Open Access This article is distributed under the terms of the Creative Commons Attribution 4.0 International License (http://creativecommons.org/licenses/by/4.0/), which permits unrestricted use, distribution, and reproduction in any medium, provided you give appropriate credit to the original author(s) and the source, provide a link to the Creative Commons license, and indicate if changes were made. The Creative Commons Public Domain Dedication waiver (http://creativecommons.org/publicdomain/zero/1.0/) applies to the data made available in this article, unless otherwise stated. 


\section{Background}

Streptococcus pneumoniae is one of the major causes of death worldwide [1, 2]. Invasive pneumococcal disease (IPD) is an important cause of disease in the elderly and young children ( $<1$ year), with an incidence rate of 13.8 and 11.3 cases per 100,000 population, respectively [1]. Other medical conditions such as transplantation also increase the risk of IPD [3-5].

In solid organ transplant (SOTR), S. pneumoniae can be a significant reason for morbidity and mortality, including non-invasive and invasive disease, with a 12.8fold greater incidence of IPD compared to the general population [4]. Specific incidences vary according to the organ transplanted, with an incidence in kidney, lung, and liver transplant recipients of 1.04, 2.39, and 3.54 per 1000 transplant recipients/year [4]. Mortality, although not significant, has been higher in SOT recipients compared with non-immunosuppressed patients $(28.6 \%$ vs. 14.1\%) $[4,6]$.

Among the virulence factors of $S$. pneumoniae, polysaccharide capsule is one of the most important. Approximately ninety different pneumococcal serotypes have been identified depending on the chemical and antigenic differences of the capsule [7], twenty of which had been described as causing most IPDs [8, 9]. The awareness of which serotypes are the most invasive has allowed the development of current vaccines [10]. In SOTR, recommendations emphasize the importance of vaccinating all candidates before transplantation $[11,12]$; however, this goal is still far from reality [13, 14]. A systematic review published by Eckerle et al. [15] in 2013 demonstrated that recommendations for the vaccination of SOTR are based on evidence from studies in healthy persons, with an urgent need to conduct vaccination trials in well-defined SOTR cohorts.

The colonization of the nasopharynx is an initial step for the evolution of IPD with transmission from human carriers [16]. Again, pneumococcal colonization has been mostly studied in children [17-19]. In healthy adults, the data about $S$. pneumoniae nasopharyngeal carriage is limited, with reported colonization rates of 4-13\% [18, 20]. Information addressing S. pneumoniae colonization in the immunosuppressed population is scarce. Despite the significance of IPD in the transplant setting, no studies address pneumococcal colonization in SOT recipients. This information would be very useful to help understand the dynamics of serotypes in this population and learn if these serotypes are included in the vaccines currently used. The information available on serotype distribution consists only of a series of cases of IPD [4, 21-23], and vaccine recommendations have been made extrapolating data from healthy children.

In this study, we describe the rate of $S$. pneumoniae colonization in SOTR in two different seasonal periods, the capsular serotypes and the antimicrobial susceptibility/ resistance pattern.

\section{Methods \\ Study design}

A prospective observational cohort of SOTR was held at the University Hospital Virgen del Rocío, Seville, Spain. All patients included met the following inclusion criteria: a) adult patients ( $\geq 16$ years); b) SOT recipients conducting their monitoring visits at the study center during the period of inclusion; c) survival after the transplant longer than 7 days; and d) written informed consent. Patients were excluded if they did not attend regular outpatient follow-up. A sample of 500 patients was included, expecting $20 \%$ of nasopharyngeal pneumococcal carriage, as in other immunosuppressed patients [3, 20, 24].

All patients were attended to in the outpatients' clinic twice: at winter (December 2014-February 2015) and six months thereafter, spring/summer (June-August 2015). In each of these dates, structured interviews, as well as microbiological studies, were carried out. Clinical data of each patient regarding demographics, household contacts, contact with pneumococcal vaccinated and unvaccinated children, previous pneumococcal and influenza vaccination, transplant-related variables such as organ type, time from the transplantation, immunosuppression regimens and prior rejection, as well as chronic co-morbidities, antibiotic use in the last three months, prior hospitalization in the previous 30 days, and respiratory symptoms were obtained.

In cases of pneumococcal disease, all needed extra visits were performed, and clinical signs and symptoms, biochemical analysis, chest X-ray findings, antiviral and antibacterial therapies, concomitant or secondary infections, and outcomes, including mortality, were recorded.

\section{Sampling and isolation}

Two different combined nasopharyngeal swab samples were obtained from each patient in both winter and spring/summer visits to increase detection rate [25, 26]. Samples were obtained by using a sterile transport swab (EO36-REV.00, COPAN, Brescia, Italy), and swabs were placed in a tube with $1.0 \mathrm{ml}$ of AMIES transport medium according to the pneumococcal carriage studies protocol of the World Health Organization $[25,26]$. The samples were cultured on Columbia Blood agar in 5\% $\mathrm{CO}_{2}$ at $37^{\circ} \mathrm{C}$, and the $\alpha$-hemolytic colonies were tested for optochin susceptibility and bile solubility [27]. Pneumococcal isolates were stored at $-80^{\circ} \mathrm{C}$ in skimmed milk until further analysis.

\section{Antimicrobial susceptibility studies}

Minimum inhibitory concentrations (MICs, mg/l) of levofloxacin, trimethoprim-sulfamethoxazole, penicillin, 
amoxicillin, cefotaxime, ceftriaxone, erythromycin, azithromycin and vancomycin for each $S$. pneumoniae isolate were determined using E-test strips [28]. MIC results were interpreted for all the antibiotics according to the Clinical \& Laboratory Standards Institute CLSI, [29] breakpoint. Studies were performed in duplicate.

\section{Capsular typing}

Isolates were typed using the modified scheme of sequential multiplex PCR protocol with sequential reactions described previously [30-32]. The serotypes studied were: $1,2,3,4,5,6 \mathrm{~A} / \mathrm{B}, 6 \mathrm{C} / \mathrm{D}, 7 \mathrm{C} / \mathrm{B} / 40,7 \mathrm{~F}, 8,9$ $\mathrm{N} / \mathrm{L}, 9 \mathrm{~V} / \mathrm{A}, 10 \mathrm{~A}, 11 \mathrm{~A} / \mathrm{D}, 12 \mathrm{~F} / \mathrm{A}, 14,15 \mathrm{~A}, 15 \mathrm{~B} / \mathrm{C}, 16 \mathrm{~F}$, 17F, 18C/A/B/F, 19A, 19F, 20, 22F/A, 23A, 23B, 23F, 31, $33 \mathrm{~F}, 34,35 \mathrm{~B}, 35 \mathrm{~F} / 47 \mathrm{~F}, 37$ and 38/25F. Briefly, each of the reactions included four serotype-specific primer pairs and a conserved region of the cps operon as internal positive control.

\section{Statistical analysis}

Data obtained in the study was analysed using the SPSS statistical software (version 24.0, SPSS Inc., Chicago, Illinois). A descriptive analysis of all data was performed. The chi-square test was used for categorical variables and the t-Student for continuous variables, when appropriate. A multivariate logistic regression analysis of factors potentially associated with pneumococcal nasopharyngeal carriage and disease was performed, including significant variables in the bivariate analyses and clinically relevant variables. Statistical significance was established at $P<0.05$.

\section{Results}

\section{Characteristics of the study population}

Five hundred SOT recipients were included in the study: 353 (70.6\%) were kidney recipients, 106 (21.2\%) liver recipients and 39 (7.9\%) heart recipients. Most patients received tacrolimus, mycophenolate and steroids as immunosuppressant therapy. Twenty-four percent of patients reported having received pneumococcal vaccination. Clinical and demographic data are shown in Table 1 . In winter 500 samples were collected, while in spring/summer 461 samples were. The difference in samples collection was due to 39 patients $(7.8 \%)$ not attending to the spring/summer visit.

\section{Pneumococcal carriage and infection}

Twenty-six patients $(5.6 \%)$ were colonized in winter and $15(3.2 \%)$ in spring/summer $(P=0.06)$. During the study period, three female patients (age range 53-71) were diagnosed with non-bacteremic pneumococcal pneumonia (Table 2); two of whom died.

The overall pneumococcal colonization rate in the 961 samples obtained was $4 \%$. There were two patients with pneumococcal colonization in both studied periods. Colonized SOT recipients compared to non-colonized patients were more frequently men $(79.5 \%$ vs. $63.1 \%, P<$ $0.05)$ and cohabitated regularly with children (59\% vs. $32.2 \%, P<0.001)$. In multivariable analysis these factors were also related to pneumococcal carriage: sex (men) OR 0.44 (CI95\% 0.20-0.98) and cohabiting with children OR 2.90 (CI95\% 1.5-5.77) (Table 3). There was no relationship between pneumococcal carriage and the immunosuppressant agents used, type of transplant or time since the transplant, pointing out that the immunosuppression was not related to the colonization status (Table 1).

Six colonized patients (15.4\%) and 115 non-colonized patients $(24.9 \%)$ had received pneumococcal vaccine prior to their inclusion $(P<0.0 .5)$. At the end of the study follow-up, 10 patients (2\%) died; 7 (1.4\%) lost the graft and $2(0.4 \%)$ suffered an organ rejection. Colonized and non-colonized SOT recipients had similar outcomes regarding the incidence of pneumococcal disease, rejection, as well as graft and patients' survival (Table 1).

\section{Characteristics of pneumococcal isolates}

During the winter period, 26 different serotypes were identified. The most prevalent serotypes were (in decreasing order): $35 \mathrm{~B}$ (38.5\%), 19A and 23A (11.5\%), 6A/ 6B, 4, 6C/D, 9 N/L and 23B (7.7\% each) (Fig. 1). Overall, $52.7 \%$ of the winter isolates were included PCV23, while $47.2 \%$ were not included. Moreover, in 8 of the winter patients $(30.8 \%)$ with pneumococcal isolates, no serotypes were identified by the molecular method used.

Sixteen isolates were resistant to azithromycin and erythromycin (36.36\%), 15 isolates to clarithromycin (34.09\%), 14 isolates to trimethoprim-sulfamethoxazole (31.82\%), 2 isolates to oral penicillin (18.18\%), and none to intravenous penicillin, amoxicillin, cefotaxime, ceftriaxone, levofloxacin and vancomycin (See Additional file 1: Table S1).

In the spring/summer period, 15 different serotypes were identified, 35B (53.3\%), 19A, 11A/D, and 38/25F (13.3\%) (In decreasing order) being the most prevalent ones (Fig. 1). Moreover, 33.3\% of the spring/summer isolates were included in PPV23, while 66.6\% were not included. The serotype of a patient of the spring/summer period $(6.7 \%)$ could not be identified with the molecular method used.

A reduction in the rate of antimicrobial resistance was observed in this period. Six isolates were resistant to trimethoprim-sulfamethoxazole (27.27\%), 4 isolates to oral penicillin, azithromycin, erythromycin and clarithromycin (18.18\%), and 2 isolates to amoxicillin (9.09\%), and as in the winter period no isolate was resistant to intravenous penicillin, cefotaxime, ceftriaxone, levofloxacin and vancomycin (See Additional file 2: Table S2). 
Table 1 Baseline characteristics and outcome of patients according to their pneumococcus colonization status

\begin{tabular}{|c|c|c|c|c|}
\hline & Total $n=500$ & Not colonized $n=461$ & Colonized $n=39$ & P OR (C195\%) \\
\hline Sex (male) - n (\%) & $322(64.4)$ & $291(63.1)$ & $31(79.5)$ & $<0.05(0.20-0.98)$ \\
\hline Age years, median (range) & $54.4(45-64)$ & $54.5(45-64)$ & $53.8(42-64)$ & ns \\
\hline \multicolumn{5}{|l|}{ Type of transplant- n (\%) } \\
\hline • Kidney & $353(70.6)$ & $324(70.3)$ & $29(74.4)$ & \multirow[t]{4}{*}{ ns } \\
\hline • Liver & $106(21.2)$ & $100(21.7)$ & $6(15.4)$ & \\
\hline • Heart & $39(7.8)$ & $35(7.6)$ & $4(10.3)$ & \\
\hline • Liver-kidney & $2(0.4)$ & $2(0.4)$ & $0(0)$ & \\
\hline \multicolumn{5}{|l|}{ Time from transplant, median (range) } \\
\hline • $0-180$ days & $94(18.8)$ & $88(19.1)$ & $6(15.4)$ & \multirow[t]{4}{*}{ ns } \\
\hline$\cdot>180-360$ days & $34(6.8)$ & $31(6.7)$ & $3(7.7)$ & \\
\hline$\cdot>1-5$ years & $139(27.8)$ & $131(28.4)$ & $8(20.5)$ & \\
\hline$\cdot>5$ years & $233(46.6)$ & $211(45.8)$ & $22(56.4)$ & \\
\hline \multicolumn{5}{|l|}{ Charlson Comorbidity Index } \\
\hline - 0 point & $110(22)$ & $103(22.3)$ & $7(17.9)$ & \multirow[t]{4}{*}{ ns } \\
\hline$\cdot 1$ points & $94(18.8)$ & $89(19.3)$ & $5(12.8)$ & \\
\hline$\cdot 2$ points & $83(16.6)$ & $76(16.5)$ & $7(17.9)$ & \\
\hline$\cdot \geq 3$ puntos & $213(42.6)$ & $193(41.9)$ & $20(51.3)$ & \\
\hline Cohabiting children- n (\%) & $172(34.4)$ & $149(32.3)$ & $23(59)$ & $0.001(1.55-5.87)$ \\
\hline - Children pneumococcal vaccination & $18(3.6)$ & $17(4.3)$ & $1(2.8)$ & ns \\
\hline Prior pneumococcal infection- $\mathrm{n}(\%)$ & $44(8.8)$ & $38(8.2)$ & $6(15.4)$ & ns \\
\hline Prior pneumococcal vaccine- $\mathrm{n}(\%)$ & $121(24.2)$ & $115(24.9)$ & $6(15.4)$ & ns \\
\hline \multicolumn{4}{|l|}{ Baseline immunosuppression- $\mathrm{n}(\%)$} & \multirow[t]{7}{*}{ ns } \\
\hline - Tacrolimus & $409(81.8)$ & $375(81.3)$ & $34(87.2)$ & \\
\hline - Mycophenolate & $377(75.4)$ & $347(75.3)$ & $30(76.9)$ & \\
\hline - Ciclosporine & $58(11.6)$ & $55(11.9)$ & $3(7.7)$ & \\
\hline • mTOR & 79 (15.8) & $75(16.3)$ & $4(10.3)$ & \\
\hline - Azathyoprine & $10(2)$ & $10(2.2)$ & $0(0)$ & \\
\hline - Glucocorticoids & $326(65.2)$ & $304(65.9)$ & $22(56.4)$ & \\
\hline Thymoglobulin induction < 6 m- n (\%) & $28(5.6)$ & $26(5.6)$ & $2(5.1)$ & ns \\
\hline Prior organ rejection & $77(15.4)$ & $70(15.2)$ & $7(17.9)$ & ns \\
\hline \multicolumn{5}{|l|}{ Outcomes: - n (\%) } \\
\hline - Pneumococcal infection & 3 & $2(0.4)$ & $1(2.5)$ & \multirow[t]{4}{*}{ ns } \\
\hline - Death & 9 & $9(2)$ & $0(0)$ & \\
\hline • Rejection & 2 & $2(0.4)$ & $0(0)$ & \\
\hline - Graft loss & 7 & $7(1.6)$ & $0(0)$ & \\
\hline
\end{tabular}

Abbreviations: OR odds ratio, Cl Confidence Interval, mTOR mammalian Target of Rapamycin, $n s$ not significant

The multiple-serotype carriage was similar in both study periods: 53.8 and $46.6 \%$, respectively. Two patients were colonized during both periods with the capsular serotype 19A, and one of them was also colonized with the capsular 35B serotype in both periods.

Taking into account all the pneumococcal isolates collected in the study $(n=57)$, the most frequent capsular serotypes were 35B (31.6\%), 19A (8.77\%) and 23A (7.02\%). Twenty-six (45.6\%) serotypes were included in any of the pneumococcal vaccines (PCV13 and PPV23), while 31 (54.4\%) serotypes were not included.

On the basis of CLSI breakpoints, the percentages of resistant isolates were $30.3 \%$ for trimethoprim-sulfamethoxazole, azithromycin and erythromycin, 28.79\% for clarithromycin, 9.09 and 3.03\% for oral penicillin and amoxicillin, respectively. No resistance was observed in the cases of intravenous penicillin, cefotaxime, ceftriaxone, levofloxacin, and vancomycin (Table 4). 
Table 2 Non-bacteraemic pneumococcal pneumonia cases in SOT recipients

\begin{tabular}{|c|c|c|c|}
\hline Cases of IPD & Case 1 & Case 2 & Case 3 \\
\hline Type of transplant & Kidney & Liver & Kidney \\
\hline Time from transplant & $0-6$ months & $>5$ years & $>5$ years \\
\hline Comorbidity & Breast and renal cancer & $\begin{array}{l}\text { Chronic renal disease, } \\
\text { hypogammaglobulinemia, and CMV infection }\end{array}$ & $\begin{array}{l}\text { Flu infection, Chronic hepatic } \\
\text { and renal diseases, hypertrophic } \\
\text { cardiomyopathy }\end{array}$ \\
\hline Prior pneumococcal vaccine & No & No & No \\
\hline Cohabiting children (children) & Yes (not vaccinated) & Yes (not vaccinated) & No \\
\hline Microbiological identification & Urinary antigen test & Bronchoalveolar lavage culture ${ }^{a}$ & Urinary antigen test \\
\hline Days of hospitalization & 4 days (general ward) & 17 days $(I C U)^{b}$ & 9 days (ICU) \\
\hline Previous colonization & No & No & Yes \\
\hline Final result & Cured & Dead & Dead \\
\hline
\end{tabular}

${ }^{\mathrm{a}}$ No capsular serotype identified; penicillin susceptible - ${ }^{\mathrm{b}} \mathrm{ICU}$, intensive care unit

\section{Discussion}

To our knowledge this is the first study conducted to evaluate pneumococcal colonization in SOT recipients. In this study we found that colonization incidence is lower than reported in other immunosuppressed patients such as HIV-infected adults [20, 24] and has no relation with the seasonal period studied. Colonized SOTR were more frequently men who cohabited with children. Moreover, almost half of the serotypes found were not included in the vaccines.

In the present study, as reported for non-immunocompromised patients [33-36], the colonization rate was less than $5 \%$ of the SOT recipients. This rate is considerably lower than that observed in healthy children (up to $54 \%)[37,38]$. Indeed, there was no relationship between pneumococcal carriage and the immunosuppressant agents used, type of transplant or time since transplantation, pointing out that the immunosuppression was not related to the colonization status.

A seasonal effect trend on the rate of pneumococcal colonization in SOTR was observed. In accordance with it, Numminen et al. [39], in a cohort of 223 infants in Asia, in 2015, concluded that climate did affect seasonal pneumococcal transmission, which acted similarly across the studied geographical regions.

On the other hand, epidemiological exposure to pneumococci, as occurs when cohabiting with children, was associated with nasopharyngeal pneumococcal

Table 3 Multivariable analysis: factors potentially related to pneumococcal nasopharyngeal carriage in solid organ transplant recipients

\begin{tabular}{lll}
\hline Variable & OR (Cl95\%) & $p$ \\
\hline Sex (male vs. female) & $0.44(0.20-0.98)$ & $\mathbf{0 . 0 4 6}$ \\
Cohabiting children (yes vs. no) & $2.95(1.50-5.77)$ & $\mathbf{0 . 0 0 2}$ \\
Prior pneumococcal vaccination (yes vs. no) & $0.59(0.24-1.45)$ & 0.247 \\
\hline
\end{tabular}

Bold data are significant

Abbreviations: $O R$ odds ratio, $C l$ Confidence Interval colonization in SOT recipients. A trend towards a higher incidence of pneumococcal nasopharyngeal carriage was also observed among non-vaccinated patients. An important issue to highlight is the low accomplishment of the recommendation of pneumococcal vaccination; only a fourth of patients had received it, which is significantly lower than that of other recommended vaccines such as influenza vaccination in the SOT population [40].

In one-fifth of the colonized patients, the serotype was non-tipable and a high serotype diversity, 21 serotypes, was observed, as reported in previous studies [36]. Of the most prevalent serotypes found, serotypes $35 \mathrm{~B}$ and $23 \mathrm{~A}$ are not included in PPV23 and PCV13 vaccines, while serotype $19 \mathrm{~A}$ is included in both vaccines. Serotype 35B has been reported as one of the most common serotypes in non-immunocompromised children and adults [41-44]. In the present study, $54.4 \%$ of serotypes colonizing SOTR were not included in current vaccines (PPV23 and PCV13). The finding of non-vaccine serotypes colonizing SOTR is a fact to be assessed given that it represents the previous step to invasive disease in susceptible patients. Moreover, it allows us to study the potential invasiveness of the more unknown serotypes, which takes advantage of the ecological niche created by the disappearance of vaccine able serotypes. Unfortunately, serotypes causing pneumococcal pneumonia could not be obtained in patients in this study and could, therefore, not be compared with those found in the nasopharinx of healthy SOTR. Despite this, the theoretical vaccine-preventable proportion of cases of IPD, using 13-valent vaccine in 2010 one year after its license in Europe, is estimated at 73\% [45]. The emergence of non-vaccine serotypes remains an important issue, and according to the European Centre for Disease Prevention and Control, continued monitoring in Europe is essential for assessing interventions and informing the development of new vaccines [1].

Few studies have analysed the serotypes of pneumococcus involved in SOTR pneumococcal diseases, most 


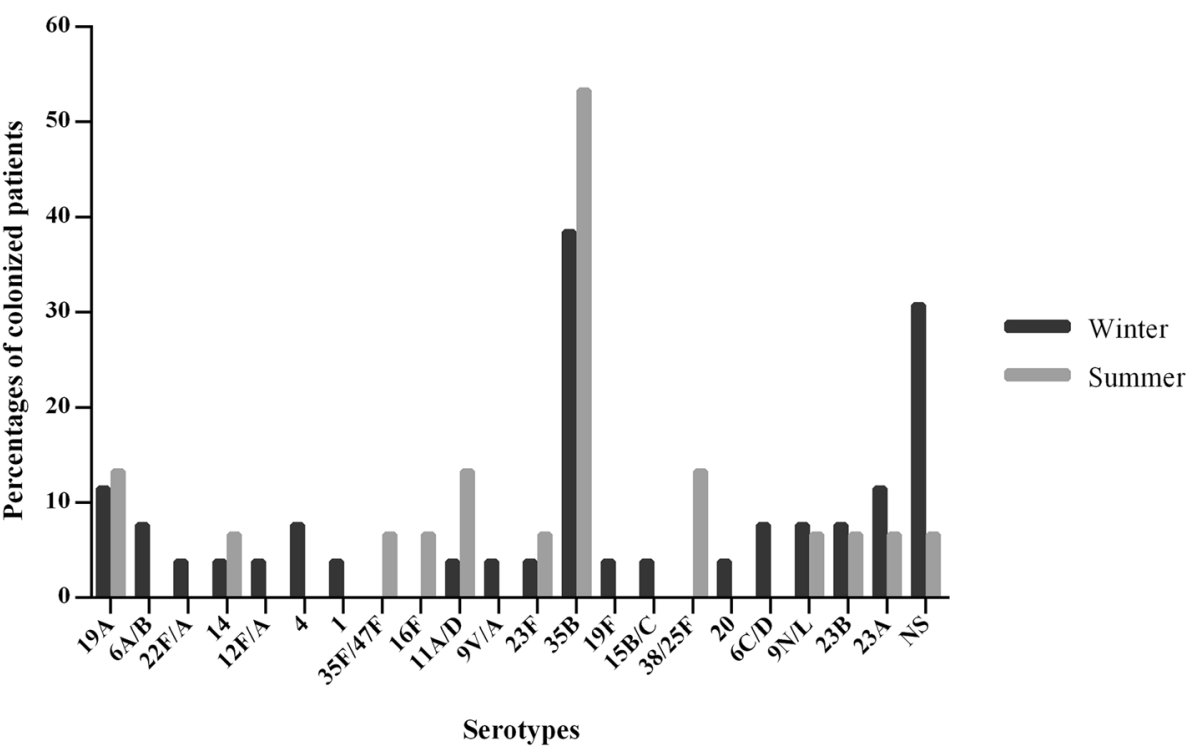

Fig. 1 Serotypes seasonal distribution of the identified pneumococcal isolates. NS: No capsular serotypes

of them including patients with IPD. A study carried out in 2013 in Spain by Lujan et al. [3] concluded that the serotypes 10A, 11A, and 33F, not included in the PCV13 vaccine, were the most frequently isolated in immunocompromised patients with IPD although their prevalence was low [3]. Kumar et al. [4] reported that the most frequent serotypes in SOT recipients with IPD were $23 \mathrm{~F}, 22 \mathrm{~F}$, and $19 \mathrm{~F}$. They reported that only onefourth of the SOT recipients with IPD had been previously vaccinated with PPV23 vaccine, and 65 and $85 \%$ of
SOT recipients suffered an invasive pneumococcal disease caused by serotypes included in the PCV13 and PPV23 vaccines, respectively [4].

One-third of the isolates during the winter season were resistant to macrolides and cotrimoxazole, and 11\% were resistant to quinolones. This proportion halved during the spring-summer season. Notably, the most prevalent serotype found (35B) presented $38 \%$ of resistance to macrolides and trimethoprim-sulfamethoxazole. Beall et al. [46], in 2002, also reported the high incidence

Table 4 In vitro activities of 11 antibiotics against S. pneumoniae clinical isolates from SOT recipients

\begin{tabular}{|c|c|c|c|c|c|}
\hline \multirow[t]{2}{*}{ Antibiotic } & \multicolumn{3}{|c|}{$\begin{array}{l}\text { CLSI breakpoints }{ }^{\mathrm{a}} \\
\text { (\% of isolates) }\end{array}$} & \multicolumn{2}{|l|}{ PK/PD } \\
\hline & Susceptible & Intermediate & Resistant & Susceptibility (\% of isolates) & Breakpoint $(\mu \mathrm{g} / \mathrm{ml})$ \\
\hline O. Penicillin & 39.39 & 51.52 & 9.09 & 39.39 & $\leq 0.06$ \\
\hline I. Penicillin & 100 & 0 & 0 & 100 & $\leq 2$ \\
\hline Amoxicillin & 87.88 & 9.09 & 3.03 & 87.88 & $\leq 2$ \\
\hline Cefotaxime & 100 & 0 & 0 & 100 & $\leq 1$ \\
\hline Ceftriaxone & 96.97 & 3.03 & 0 & 96.97 & $\leq 1$ \\
\hline Azithromycin & 53.03 & 16.67 & 30.30 & 53.03 & $\leq 0.5$ \\
\hline Erythromycin & 66.67 & 3.03 & 30.30 & 66.67 & $\leq 0.25$ \\
\hline Clarithromycin & 71.21 & 0 & 28.79 & 71.21 & $\leq 0.25$ \\
\hline Levofloxacin & 75.76 & 24.24 & 0 & 75.76 & $\leq 2$ \\
\hline Vancomycin & 100 & 0 & 0 & 100 & $\leq 1$ \\
\hline Trimethoprim-sulfamethoxazole & 53.03 & 16.67 & 30.30 & 53.03 & $\leq 0.5$ \\
\hline
\end{tabular}

Abbreviations: $O$ oral, $I$ intravenous

${ }^{a}$ The CLSI breakpoints used were $\leq 0.06 \mathrm{mg} / \mathrm{L}$ (susceptible), 0.12 to $1 \mathrm{mg} / \mathrm{L}$ (intermediate), and $\geq 2 \mathrm{mg} / \mathrm{L}$ (resistant) for oral penicillin and $\leq 2 \mathrm{mg} / \mathrm{L}$ (susceptible), 4 $\mathrm{mg} / \mathrm{L}$ (intermediate), and $\geq 8 \mathrm{mg} / \mathrm{L}$ (resistant) for intravenous penicillin; $\leq 2 \mathrm{mg} / \mathrm{L}$ (susceptible), $4 \mathrm{mg} / \mathrm{L}$ (intermediate), and $\geq 8 \mathrm{mg} / \mathrm{L}$ (resistant) for amoxicillin; $\leq 1 \mathrm{mg} /$ $\mathrm{L}$ (susceptible), $2 \mathrm{mg} / \mathrm{L}$ (intermediate), and $\geq 4 \mathrm{mg} / \mathrm{L}$ (resistant) for cefotaxime and ceftriaxone; $\leq 0.5 \mathrm{mg} / \mathrm{L}$ (susceptible), $1 \mathrm{mg} / \mathrm{L}$ (intermediate), and $\geq 2 \mathrm{mg} / \mathrm{L}$ (resistant) for azithromycin; $\leq 0.25 \mathrm{mg} / \mathrm{L}$ (susceptible), $0.5 \mathrm{mg} / \mathrm{L}$ (intermediate), and $\geq 1 \mathrm{mg} / \mathrm{L}$ (resistant) for erythromycin and clarithromycin; $\leq 2 \mathrm{mg} / \mathrm{L}$ (susceptible), $4 \mathrm{mg} / \mathrm{L}$ (intermediate), and $\geq 8 \mathrm{mg} / \mathrm{L}$ (resistant) for levofloxacin; $\leq 1 \mathrm{mg} / \mathrm{L}$ (susceptible) for vancomycin; and $\leq 0.5 \mathrm{mg} / \mathrm{L}$ (susceptible), $1-2 \mathrm{mg} / \mathrm{L}$ (intermediate), and $\geq$ $4 \mathrm{mg} / \mathrm{L}$ (resistant) for trimethoprim-sulfamethoxazole 
of invasive serotype 35B in the US. In that study, 68 isolates (69\%) were non-susceptible to penicillin; all of them with decreased susceptibility or non-susceptibility to cefotaxime and 11 isolates $(16 \%)$ were resistant to trimethoprim-sulfamethoxazole. Moreover, in the present study, one penicillin-resistant isolate was highly resistant to cefotaxime (MIC, $8 \mu \mathrm{g} / \mathrm{ml}$ ) and resistant to trimethoprim-sulfamethoxazole, tetracycline, erythromycin, clindamycin, and chloramphenicol. It is still not defined whether the resistance of certain serotypes to penicillin is due to innate biological features or the high usage of $\beta$-lactams antibiotics [46]. A higher resistance of the serotype $35 \mathrm{~B}$ has been reported recently from isolates causing IPD in children, with $91 \%$ of the isolates penicillin non-susceptible, $46.2 \%$ erythromycin resistant, $21.8 \%$ trimethoprim-sulfamethoxazole resistant, and $16.7 \%$ were considered multidrug-resistant [42].

There were three cases of non-bacteraemia pneumococcal pneumonia during the study, only one of them previously colonized. However, two out of the three patients died, both with important comorbidities. None of these patients was previously vaccinated against pneumococcus. The absence of previous vaccination in SOTR had been linked to unfavourable IPD outcomes [46]. Although the number of cases with non-bacteraemia pneumococcal pneumonia was too low in our study to establish robust conclusions, we consider that the unfavourable outcome strengthens the recommendation for pneumococcal vaccination in SOTR [47].

We should point out some limitations of this study. First, it is possible that some mild cases of pneumococcal disease were not diagnosed; however, no IPD cases were missed since all patients were carefully reviewed and guided to report any respiratory symptoms or fever during the study period. Secondly, the small number of cases of pneumococcal pneumonia did not permit to stablish a robust association with the lack of pneumococcal vaccination. Finally, there was no official record of pneumococcal vaccination; consequently, this information is missing for $22.4 \%$ of the patients.

\section{Conclusions}

The present study shows that the rate of pneumococcal colonization in SOTR is low, similar to that reported in the general adult population. The incidence of nonbacteremic pneumococcal pneumonia was low, although two out of the three patients died, suggesting the need of pneumococcal vaccination for the SOTR.

\section{Additional files}

Additional file 1: Table S1. In vitro activities of 11 antibiotics against $S$. pneumoniae clinical isolates from SOT recipients in winter (DOCX $31 \mathrm{~kb}$ )

Additional file 2: Table S2. In vitro activities of 11 antibiotics against $S$. pneumoniae clinical isolates from SOT recipients in summer (DOCX $18 \mathrm{~kb}$ )

\section{Abbreviations}

CLSI: Clinical \& Laboratory Standards Institute; IPD: Invasive pneumococcal disease; MICs: Minimum inhibitory concentrations; SOTR: Solid organ transplant recipient

\section{Acknowledgements}

The authors are grateful to the participants that collaborated in the study. This work was presented in part at the 27th congress ECCMID is a European Congress of Clinical Microbiology and Infectious Diseases.

\section{Authors' contributions}

CRO and TCC contributed equally to this work (joint first authors). CRO and TCC performed the experiments, analysed the results and wrote the manuscript. MGM and GLH helped performing the experiments. YS reviewed the manuscript. LMG and FGR included the patients in the study and reviewed the manuscript. JP helped with interpretation of the data, and revision of the manuscript. MPI designed and coordinated the experiments, and reviewed the results and the manuscript. EC obtained the funds to perform the studies and reviewed analysis and manuscript. All authors approved of the final draft.

\section{Funding}

The present work has been supported by Pfizer, 2014 ASPIRE Awards in Vaccine Research in Europe (Pfizer Reference \# WI191483),by Plan Nacional de I+D + i 2013-2016 and Instituto de Salud Carlos III, Subdirección General de Redes y Centros de Investigación Cooperativa, Ministerio de Economía, Industria y Competitividad, Spanish Network for Research in Infectious Diseases (REIPI RD16/0016/0009) - co-financed by European Development Regional Fund "A way to achieve Europe", Operative program Intelligent Growth 2014-2020.

The funders had no role in study design, data collection and analysis, decision to publish, or preparation of the manuscript.

\section{Availability of data and materials}

The data used and/or analysed during the study are on the manuscript, any other data and or analysis are available from the corresponding author.

\section{Ethics approval and consent to participate}

The study was approved by the Ethical and Scientific Committees of the University Hospital Virgen del Rocío, Seville, Spain, and the Ministry of Health of la Junta de Andalucía, Spain (\#PCV-IIG-2 [WI191483]). All patients provided written informed consent.

\section{Consent for publication}

Not applicable.

\section{Competing interests}

The authors declare that they have no competing interests.

\section{Author details}

${ }^{1}$ Clinical Unit of Infectious Diseases, Microbiology, and Preventive Medicine Infectious Diseases Research Group Institute of Biomedicine of Seville (IBiS), University of Seville/CSIC/University Hospital Virgen del Rocío, Seville, Spain. ${ }^{2}$ Institute of Biomedicine of Seville (IBiS), University of Seville/CSIC/University Hospital Virgen del Rocio Seville, Seville, Spain. ${ }^{3}$ Urology and Nephrology

Unit, University Hospital Virgen del Rocío, Seville, Spain. ${ }^{4}$ Clinical Unit of

General Surgery, University Hospital Virgen del Rocío, Seville, Spain.

${ }^{5}$ Department of Medicine, University of Seville, Seville, Spain.

Received: 23 April 2019 Accepted: 26 July 2019

Published online: 06 August 2019

\section{References}

1. Annual epidemiological report 2016. European Centre for Disease Prevention and Control 2016.

2. Prevention CfDCa. Active Bacterial Core surveillance (ABCs). 2013 -present.

3. Lujan M, Burgos J, Gallego M, Falco V, Bermudo G, Planes A, et al. Effects of immunocompromise and comorbidities on pneumococcal serotypes causing invasive respiratory infection in adults: implications for vaccine strategies. Clinical infectious diseases : an official publication of the Infectious Diseases Society of America. 2013;57(12):1722-30. 
4. Kumar D, Humar A, Plevneshi A, Green K, Prasad GV, Siegal D, et al. Invasive pneumococcal disease in solid organ transplant recipients--10-year prospective population surveillance. Am J Transplant Off J Am Soc Transplant Am Soc Transplant Surg. 2007;7(5):1209-14.

5. Cordero E, Pachon J, Rivero A, Giron JA, Gomez-Mateos J, Merino MD, et al. Community-acquired bacterial pneumonia in human immunodeficiency virus-infected patients: validation of severity criteria. The Grupo Andaluz Para el Estudio de las Enfermedades Infecciosas. Am J Respir Crit Care Med. 2000;162(6):2063-8.

6. Yu VL, Chiou CC, Feldman C, Ortqvist A, Rello J, Morris AJ, et al. An international prospective study of pneumococcal bacteremia: correlation with in vitro resistance, antibiotics administered, and clinical outcome. Clinical infectious diseases : an official publication of the Infectious Diseases Society of America. 2003;37(2):230-7.

7. Song JY, Nahm MH, Moseley MA. Clinical implications of pneumococcal serotypes: invasive disease potential, clinical presentations, and antibiotic resistance. J Korean Med Sci. 2013;28(1):4-15.

8. III SAIMCNdEIdSC. INFORME ANUAL del SISTEMA de INFORMACIÓN MICROBIOLÓGICA 2012. 2014.

9. Hausdorff WP, Bryant J, Paradiso PR, Siber GR. Which pneumococcal serogroups cause the most invasive disease: implications for conjugate vaccine formulation and use, part I. Clinical infectious diseases : an official publication of the Infectious Diseases Society of America. 2000;30(1):100-21.

10. Prevention of pneumococcal disease: recommendations of the Advisory Committee on Immunization Practices (ACIP). MMWR Recommendations and reports : Morbidity and mortality weekly report Recommendations and reports. 1997;46(RR-8):1-24.

11. (CDC). CfDCaP. Use of 13-valent pneumococcal conjugate vaccine and 23valent pneumococcal polysaccharide vaccine for adults with immunocompromising conditions: recommendations of the advisory committee on immunization practices (ACIP). MMWR Morb Mortal Wkly Rep. 2012;61(40):816-9.

12. Danziger-Isakov L, Kumar D. Practice ASTIDCo. Vaccination in solid organ transplantation. Am J Transplant Off J Am Soc Transplant Am Soc Transplant Surg. 2013;13(Suppl 4):311-7.

13. Harris K, Baggs J, Davis RL, Black S, Jackson LA, Mullooly JP, et al. Influenza vaccination coverage among adult solid organ transplant recipients at three health maintenance organizations, 1995-2005. Vaccine. 2009;27(17):2335-41.

14. Diana A, Posfay-Barbe KM, Belli DC, Siegrist CA. Vaccine-induced immunity in children after orthotopic liver transplantation: a 12-yr review of the Swiss national reference center. Pediatr Transplant. 2007;11(1):31-7.

15. Eckerle I, Rosenberger KD, Zwahlen M, Junghanss T. Serologic vaccination response after solid organ transplantation: a systematic review. PLoS One. 2013;8(2):e56974.

16. van der Poll T, Opal SM. Pathogenesis, treatment, and prevention of pneumococcal pneumonia. Lancet. 2009;374(9700):1543-56.

17. Obando I, Sanchez-Tatay D, Molinos-Quintana A, Delgado-Pecellin I, Porras A, Morillo-Gutierrez B, et al. Epidemiology of nasopharyngeal carriage of Streptococcus pneumoniae in children $<6$ years old in Seville. Enferm Infecc Microbiol Clin. 2011;29(8):581-6.

18. Regev-Yochay G, Raz M, Dagan R, Porat N, Shainberg B, Pinco E, et al. Nasopharyngeal carriage of Streptococcus pneumoniae by adults and children in community and family settings. Clinical infectious diseases : an official publication of the Infectious Diseases Society of America. 2004;38(5):632-9.

19. Bogaert D, De Groot R, Hermans PW. Streptococcus pneumoniae colonisation: the key to pneumococcal disease. Lancet Infect Dis. 2004;4(3): 144-54.

20. Glennie SJ, Banda D, Gould K, Hinds J, Kamngona A, Everett DD, et al. Defective pneumococcal-specific Th1 responses in HIV-infected adults precedes a loss of control of pneumococcal colonization. Clinical infectious diseases : an official publication of the Infectious Diseases Society of America. 2013;56(2):291-9.

21. Linnemann CC Jr, First MR. Risk of pneumococcal infections in renal transplant patients. Jama. 1979;241(24):2619-21.

22. Amber IJ, Gilbert EM, Schiffman G, Jacobson JA. Increased risk of pneumococcal infections in cardiac transplant recipients. Transplantation. 1990;49(1):122-5.

23. de Bruyn G, Whelan TP, Mulligan MS, Raghu G, Limaye AP. Invasive pneumococcal infections in adult lung transplant recipients. Am J Transplant Off J Am Soc Transplant Am Soc Transplant Surg. 2004:4(8):1366-71.
24. Nicoletti C, Brandileone MC, Guerra ML, Levin AS. Prevalence, serotypes, and risk factors for pneumococcal carriage among HIV-infected adults. Diagn Microbiol Infect Dis. 2007;57(3):259-65.

25. Gladstone RA, Jefferies JM, Faust SN, Clarke SC. Sampling methods for the study of pneumococcal carriage: a systematic review. Vaccine. 2012;30(48): 6738-44.

26. O'Brien $\mathrm{KL}$, Nohynek $\mathrm{H}$. World health organization pneumococcal vaccine trials carriage working $\mathrm{G}$. report from a WHO working group: standard method for detecting upper respiratory carriage of Streptococcus pneumoniae. Pediatr Infect Dis J. 2003;22(2):e1-11.

27. Ing J, Mason EO, Kaplan SL, Lamberth LB, Revell PA, Luna RA, et al. Characterization of nontypeable and atypical Streptococcus pneumoniae pediatric isolates from 1994 to 2010. J Clin Microbiol. 2012;50(4):1326-30.

28. Ma X, Zhao R, Ma Z, Yao K, Yu S, Zheng Y, et al. Serotype distribution and antimicrobial resistance of Streptococcus pneumoniae isolates causing invasive diseases from Shenzhen Children's hospital. PLoS One. 2013;8(6): e67507.

29. CLSI CaLSI-. Performance Standards for Antimicrobial Susceptibility Testing Clinical and Laboratory Standards Institute 2018.

30. Iraurgui P, Torres MJ, Gandia A, Vazquez I, Cabrera EG, Obando I, et al. Modified sequential multiplex PCR for determining capsular serotypes of invasive pneumococci recovered from Seville. Clinical microbiology and infection : the official publication of the European Society of Clinical Microbiology and Infectious Diseases. 2010;16(9):1504-7.

31. Gillis HD, Demczuk WHB, Griffith A, Martin I, Warhuus M, Lang ALS, et al. PCR-based discrimination of emerging Streptococcus pneumoniae serotypes 22F and 33F. J Microbiol Methods. 2018;144:99-106.

32. Shakrin NN, Balasubramaniam SD, Yusof HA, Mastuki MF, Masri SN, Taib NM, et al. Evaluation of PCR-based approach for serotype determination of Streptococcus pneumoniae. Trop Biomed. 2013;30(2):338-44.

33. Abdullahi O, Nyiro J, Lewa P, Slack M, Scott JA. The descriptive epidemiology of Streptococcus pneumoniae and Haemophilus influenzae nasopharyngeal carriage in children and adults in Kilifi district, Kenya. Pediatr Infect Dis J. 2008;27(1):59-64.

34. Flamaing J, Peetermans WE, Vandeven J, Verhaegen J. Pneumococcal colonization in older persons in a nonoutbreak setting. J Am Geriatr Soc. 2010;58(2):396-8.

35. Palmu AA, Kaijalainen T, Saukkoriipi A, Leinonen M, Kilpi TM. Nasopharyngeal carriage of Streptococcus pneumoniae and pneumococcal urine antigen test in healthy elderly subjects. Scand J Infect Dis. 2012;44(6): 433-8.

36. Almeida ST, Nunes S, Santos Paulo AC, Valadares I, Martins S, Breia F, et al. Low prevalence of pneumococcal carriage and high serotype and genotype diversity among adults over 60 years of age living in Portugal. PLoS One. 2014;9(3):e90974.

37. Allemann A, Frey PM, Brugger SD, Hilty M. Pneumococcal carriage and serotype variation before and after introduction of pneumococcal conjugate vaccines in patients with acute otitis media in Switzerland. Vaccine. 2017;35(15):1946-53.

38. Ousmane S, Diallo BA, Ouedraogo R, Sanda AA, Soussou AM, Collard JM. Serotype distribution and antimicrobial sensitivity profile of Streptococcus pneumoniae carried in healthy toddlers before PCV13 introduction in Niamey. Niger PloS one. 2017;12(1):e0169547.

39. Numminen E, Chewapreecha C, Turner C, Goldblatt D, Nosten F, Bentley SD, et al. Climate induces seasonality in pneumococcal transmission. Sci Rep. 2015;5:11344.

40. Cordero E, Roca-Oporto C, Bulnes-Ramos A, Aydillo T, Gavalda J, Moreno A, et al. Two doses of inactivated influenza vaccine improve immune response in solid organ transplant recipients: results of TRANSGRIPE 1-2, a randomized controlled clinical trial. Clinical infectious diseases : an official publication of the Infectious Diseases Society of America. 2017;64(7):829-38.

41. Miyazaki H, Shibuya R, Midorikawa N, Chang B, Ohnishi M, Matsumoto T. Serotype distribution and antimicrobial susceptibility of Streptococcus pneumoniae strains isolated in Japan after introduction of the routine immunization program. Journal of infection and chemotherapy : official journal of the Japan Society of Chemotherapy. 2017;23(4):234-40.

42. Olarte L, Kaplan SL, Barson WJ, Romero JR, Lin PL, Tan TQ, et al. Emergence of multidrug-resistant pneumococcal serotype 35B among children in the United States. J Clin Microbiol. 2017;55(3):724-34.

43. Mendes RE, Hollingsworth RC, Costello A, Jones RN, Isturiz RE, Hewlett D Jr, et al. Noninvasive Streptococcus pneumoniae serotypes recovered from 
hospitalized adult patients in the United States in 2009 to 2012. Antimicrob Agents Chemother. 2015;59(9):5595-601.

44. Ubukata K, Chiba N, Hanada S, Morozumi M, Wajima T, Shouji M, et al.

Serotype changes and drug resistance in invasive pneumococcal diseases in adults after vaccinations in children, Japan, 2010-2013. Emerg Infect Dis. 2015;21(11):1956-65

45. (ECDC) ECfDPaC. Surveillance of invasive pneumococcal disease in Europe, 2010. 2012.

46. Beall B, McEllistrem MC, Gertz RE Jr, Boxrud DJ, Besser JM, Harrison LH, et al. Emergence of a novel penicillin-nonsusceptible, invasive serotype $35 B$ clone of Streptococcus pneumoniae within the United States. J Infect Dis. 2002; 186(1):118-22.

47. van Veen KE, Brouwer MC, van der Ende A, van de Beek D. Bacterial meningitis in solid organ transplant recipients: a population-based prospective study. Transplant infectious disease : an official journal of the Transplantation Society. 2016;18(5):674-80.

\section{Publisher's Note}

Springer Nature remains neutral with regard to jurisdictional claims in published maps and institutional affiliations.

Ready to submit your research? Choose BMC and benefit from:

- fast, convenient online submission

- thorough peer review by experienced researchers in your field

- rapid publication on acceptance

- support for research data, including large and complex data types

- gold Open Access which fosters wider collaboration and increased citations

- maximum visibility for your research: over $100 \mathrm{M}$ website views per year

At BMC, research is always in progress.

Learn more biomedcentral.com/submissions 